\title{
The Antioxidant Status in Rheumatoid Arthritis
}

\author{
Ganesan NALINI, ${ }^{1, *}$ Chegu HARIPRASAD,${ }^{1}$ Arungunram Nagarajan \\ CHANDRASEKARAN, ${ }^{2}$ Chandrakasan Gowri, ${ }^{3}$ and \\ Kailash POONGUZHALI ${ }^{1}$ \\ ${ }^{1}$ Department of Biochemistry, Sri Ramachandra Medical College and Research \\ Institute, Deemed University, Porur, Madras 600 116, India \\ ${ }^{2}$ Department of Rheumatology, Government General Hospital, Madras \\ Medical College, Madras 600 003, India \\ ${ }^{3}$ Department of Biochemistry, Central Leather Research Institute, \\ Adyar, Madras 600 020, India
}

(Received January 6, 1997)

\begin{abstract}
Summary In the present work, we studied the antioxidant status in the blood of a group $(n=29)$ of rheumatoid arthritis (RA) patients and compared it with that of a control group $(n=30)$. There was a significant increase $(p<0.001)$ in the plasma lipid peroxide level, but no change in the plasma ascorbic acid level, when the RA group was compared with the control group. There was a significant decrease in reduced glutathione (GSH, $p<0.01)$ and in glutathione peroxidase (GPX, $p<0.05$ ) and superoxide dismutase (SOD, $p<0.001$ ) activities in the hemolysate of RA patients when compared with the control group values. A good correlation was obtained between the parameters estimated in the hemolysate. This study reflects the oxidative stress as a result of altered antioxidant status in the blood of RA patients, which findings may have implications in the pathogenesis of the disease.
\end{abstract}

Key Words: antioxidants, hemolysate, rheumatoid arthritis, malondialdehyde, oxidative stress

Free radicals are highly reactive and unstable entities capable of damaging cellular components, and they contribute to the pathogenesis of a number of diseases [1]. There is accumulating evidence that rheumatoid arthritis (RA) patient has many characteristics of a free radical-produced disease [2]. The monocytes from some RA patients have enhanced potential to generate oxygen free radicals [3]. In vitro studies have also emphasized the potential role of oxygen free

*To whom correspondence should be addressed. 
radicals in the damage to the connective tissue constituents including hyaluronic acid [4] and collagen [5]. The damage to these macromolecules in turn alters immune function [6].

RA is a disease characterized by destruction of joint structures such as the synovium, cartilage, and bone. The cellular and biochemical events that bring about inflammation and tissue destruction are complex, and critical control mechanisms remain to be defined [7]. We observed a significant increase in serum adenosine deaminase and cytidine deaminase activities in our RA patients and demonstrated that these can be used as biochemical markers of immunoinflammation along with other measures such as ESR and CRP [8]. We also observed an overall increase in urinary glycosaminoglycans in a small group of RA patients when the level was compared with that of the control group [9]. In the present study, we were interested to see if there is any change in the biochemical parameters that are responsible for the antioxidant status in our RA patients.

In normal cellular life, the damage by the free radicals is kept to a minimum by the existence of defense mechanisms. No living systems other than the red cell meets the requirements favorable for lipid peroxidation [10].

In the rheumatoid arthritic joint, a glucose-deficient synovium [11] may during reperfusion use lipolysis to maintain energy demands or the lipids may become oxidatively modified by free radicals. The changes taking place in the joint may be reflected in the blood. Therefore, in the present study, we decided to determine the glutathione content and the activities of superoxide dismutase (SOD), glutathione peroxidase (GPX), and reduced glutathione (GSH) in the hemolysate, to estimate the extent of lipid peroxidation through malondialdehyde and to measure the plasma level of the antioxidant ascorbic acid. The antioxidant status in RA may have an indirect role in the pathogenesis of the disease.

\section{PATIENTS AND CONTROL GROUP}

The patients chosen for the study were those who attended the Rheumatology Clinic Government General Hospital in Madras, India. This group consisted of 29 patients undergoing treatment and who fulfilled the American Rheumatism Criteria for RA [12]. The control group consisted of 30 healthy persons of the same age range as the patient group. All the patients were suffering from severe $\mathrm{RA}$, and were receiving 2 nd-line medication (chloroquine $(n=27)$ or $\mathrm{D}$ penicillamine $(n=2))$. The characteristics of the control group and the patient group regarding the age range, sex ratio are shown in Table 1.

Table 1. Characteristics of control and patients.

\begin{tabular}{|c|c|c|c|c|c|}
\hline \multirow{2}{*}{ Group } & \multirow{2}{*}{ No. of cases } & \multicolumn{2}{|c|}{ Sex } & \multirow{2}{*}{$\begin{array}{l}\text { Age in } \\
\text { years }\end{array}$} & \multirow{2}{*}{$\begin{array}{l}\text { Duration of the } \\
\text { disease in years }\end{array}$} \\
\hline & & Male & Female & & \\
\hline Control & 30 & 10 & 20 & $19-60$ & - \\
\hline RA & 29 & 6 & 23 & $20-61$ & $4-10$ \\
\hline
\end{tabular}




\section{MATERIALS AND METHODS}

Collection of sample. The blood was collected in clean, sterile tube containing heparin as the anticoagulant. The heparinized blood samples were centrifuged at 4,000 rpm for $10 \mathrm{~min}$ and the plasma was separated and used for the estimation of ascorbic acid and lipid peroxide.

Preparation of hemolysate. After centrifugation the cells were freed of plasma and the buffy coat was removed. The red cells were washed four times with $0.9 \%$ saline by centrifugation for $10 \mathrm{~min}$ at $3,000 \mathrm{rpm}$ after each wash. The cell lysis was carried out by adding an equal volume of ice-cold redistilled water to a given volume of washed cells. This diluted suspension was allowed to stand for $2 \mathrm{~h}$ at $4^{\circ} \mathrm{C}$. The hemolysate was used for the estimation of GSH, GPX, SOD, and hemoglobin. All the estimations were carried out between 12 and $24 \mathrm{~h}$ after sampling.

Estimations in the plasma. The plasma ascorbic acid was estimated by the method of Omaye et al. [13] and expressed as mg\%. The plasma lipid peroxide was measured by the thiobarbituric acid reaction by the method of Yagi et al. [14] and expressed as $\mathrm{nmol} / \mathrm{ml}$ of plasma.

Estimations in the hemolysate. The GSH in hemolysates was estimated by the method of Moron et al. [15] and expressed as micrograms of GSH/mg Hb. The GPX activity in the hemolysate was estimated by the method of Rotruck et al. [16] and expressed as micrograms of $\mathrm{GSH}$ utilized $/ \mathrm{min} / \mathrm{mg} \mathrm{Hb}$, and the SOD activity in the hemolysate, by the auto-oxidation of pyrogallol as described by Marklund and Marklund [17]. One unit of the latter enzyme activity corresponds to the amount of the enzyme that inhibits the reaction by $50 \%$ and was expressed as $\mathrm{U} / \mathrm{ml}$ hemolysate. The hemoglobin in the hemolysate was measured according to Drabkin and Austin [18].

Statistical analysis. The statistical analysis was done by Student's $t$-test. The values were expressed as mean $\pm \mathrm{SD}$. Pearson's correlation coefficient, " $r$," was calculated for pairs of parameters assayed in the hemolysate.

\section{RESULTS}

The results are shown in Table 2 . In the patient group there was a significant increase in plasma lipid peroxide level $(p<0.001)$ but no observable change in the plasma ascorbic acid values when the RA values were compared with the control group ones. In the hemolysate, the activities of SOD, and GPX and the GSH content were significantly reduced ( $p<0.001, p<0.05$, and $p<0.01$, respectively) when these values were compared with those of the control group. The SOD, GPX, and GSH levels within the control group were closely correlated ( $p<0.001$, Fig. 1 $\mathrm{a}-\mathrm{c})$ and the same was true for the RA group ( $p<0.001$, Fig. $2 \mathrm{a}-\mathrm{c})$. 
Table 2. Lipid peroxides and antioxidant levels.

\begin{tabular}{lcccccc}
\hline & \multicolumn{2}{c}{ Plasma } & & \multicolumn{3}{c}{ Hemolysate } \\
\cline { 2 - 3 } \cline { 5 - 6 } Groups & $\begin{array}{c}\text { Lipid peroxide } \\
\text { level } \\
(\mathrm{nmol} / \mathrm{ml})\end{array}$ & $\begin{array}{c}\text { Ascorbic } \\
\text { acid } \\
(\mathrm{mg} \%)\end{array}$ & & $\begin{array}{c}\text { SOD } \\
(\mathrm{U} / \mathrm{ml})\end{array}$ & $\begin{array}{c}\text { GSH } \\
(\mu \mathrm{g} / \mathrm{mg} \mathrm{Hb})\end{array}$ & $\begin{array}{c}\text { GPX of GSH utilized } / \\
\mathrm{min} / \mathrm{mg} \mathrm{Hb})\end{array}$ \\
\hline $\begin{array}{l}\text { Control } \\
(n=30)\end{array}$ & $2.493 \pm 1.42$ & $0.437 \pm 0.11$ & & $2.726 \pm 1.50$ & $3.63 \pm 0.93$ & $3.847 \pm 2.19$ \\
$\begin{array}{l}\text { RA } \\
(n=29)\end{array}$ & $6.709 \pm 1.54^{* * *}$ & $0.432 \pm 0.28$ & & $1.447 \pm 0.56^{* * *}$ & $2.812 \pm 1.15^{* *}$ & $2.502 \pm 2.25^{*}$ \\
\hline
\end{tabular}

The values are expressed as the mean $\pm \mathrm{SD} .{ }^{* * *} p<0.001,{ }^{* *} p<0.01,{ }^{*} p<0.05$, vs. control value.
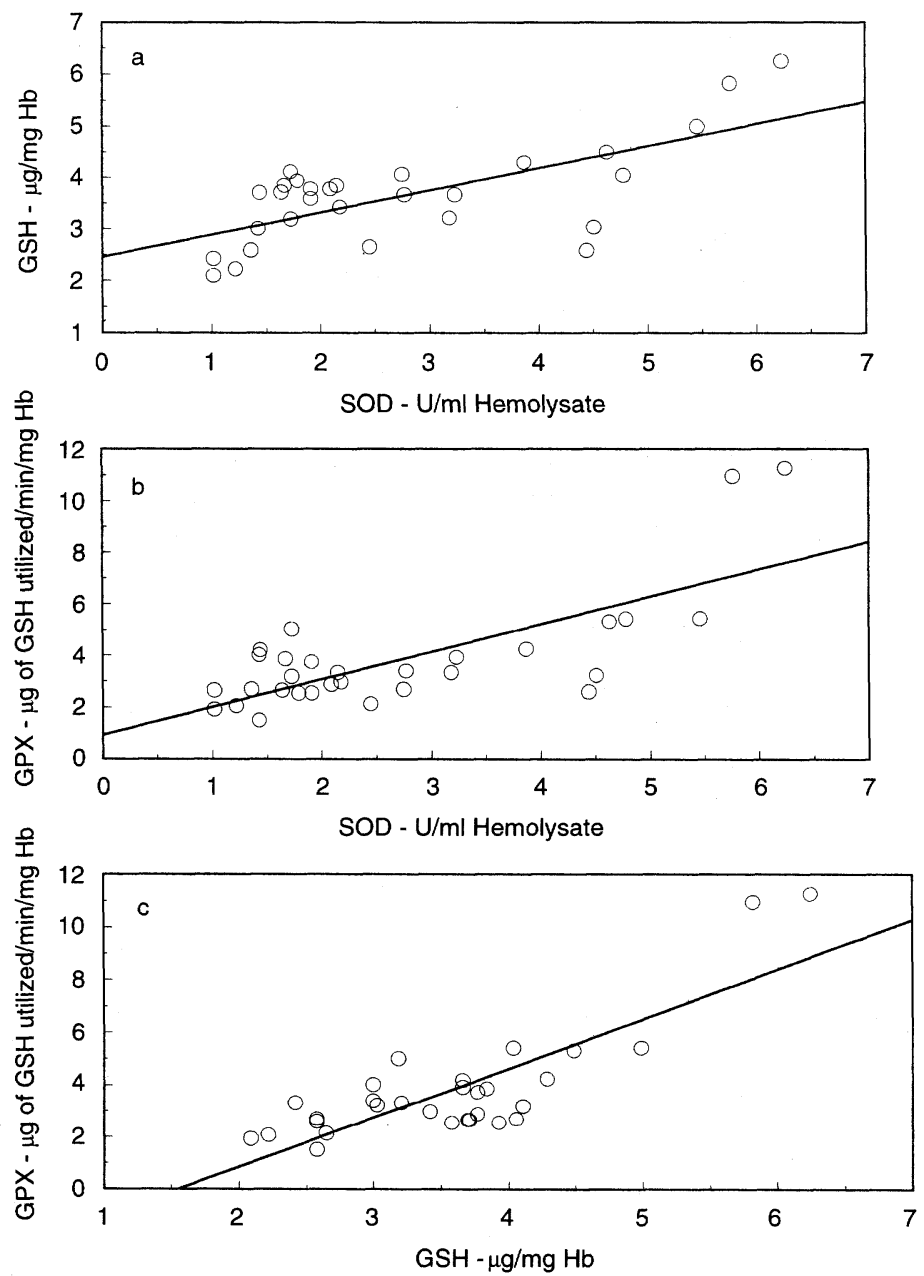

Fig. 1. Correlation between parameters measured in normals. (a) between SOD and GSH ( $r=0.69, p<0.001)$; (b) between SOD and GPX $(r=0.74, p<0.001)$; (c) between GSH and GPX $(r=0.86, p<0.001)$. 

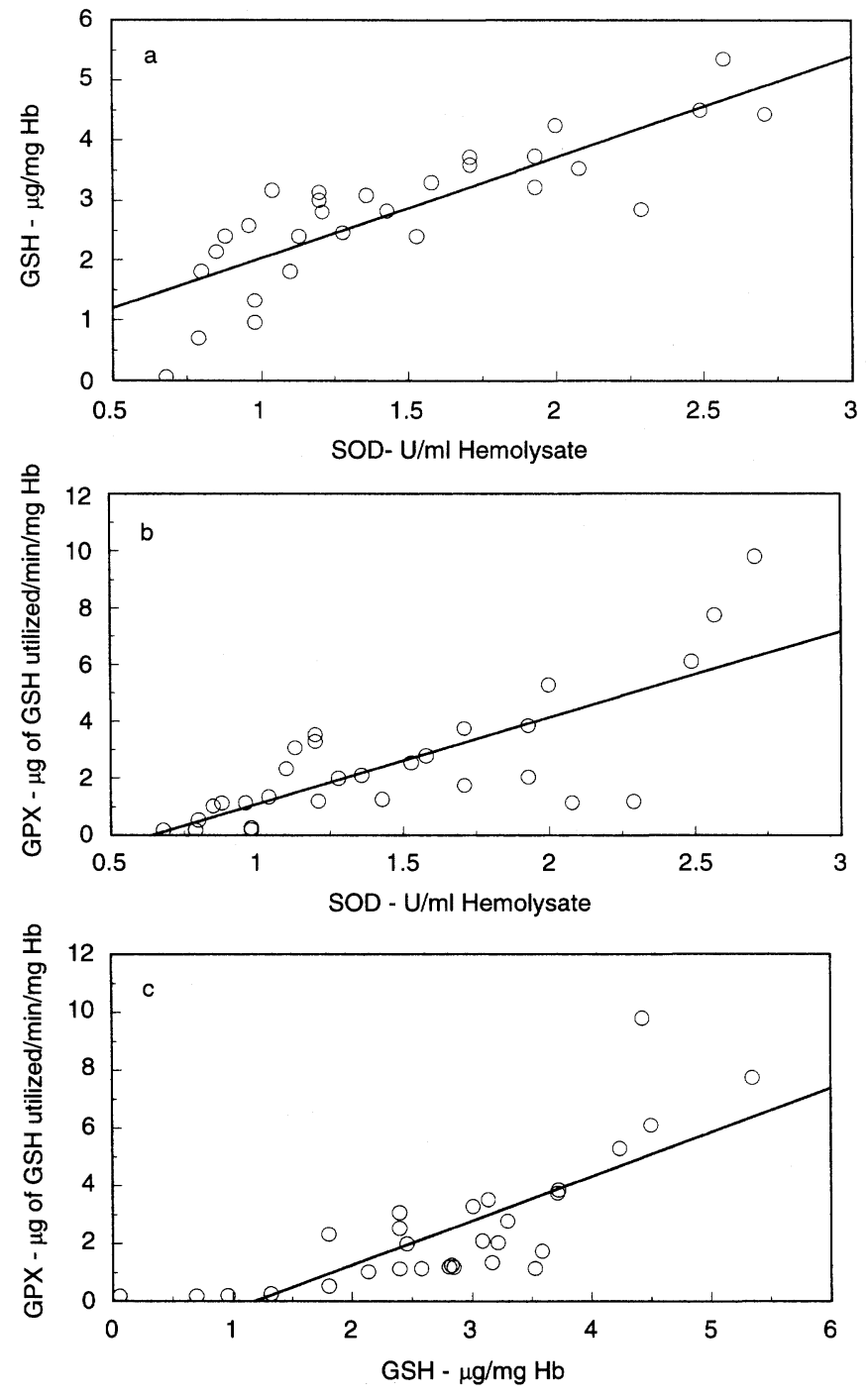

Fig. 2. Correlation between parameters measured in RA. (a) between SOD and GSH ( $r=$ $0.83, p<0.001)$; (b) between SOD and GPX $(r=0.82, p<0.001)$; (c) between GSH and GPX $(r=0.61, p<0.001)$.

\section{DISCUSSION}

In the present study, there was a significant increase in the plasma lipid peroxide level in the RA patients. Our results are consistent with the studies by Lunec et al. [19] who observed increased levels of lipid peroxidation reaction in the synovial fluid and plasma of patients with active RA. The disturbed immuno- 
reactivity of the synovial fluid lymphocytes in RA may also be mediated by free radicals [20]. The aldehyde products of the oxidative process are thought to alter the $\mathrm{T}$ cell/macrophage interactions and thus contribute to the pathogenesis of the disease [6]. We observed no change in the ascorbic acid level, which may indicate that all the antioxidants need not act in the same way as the other defense systems.

In the hemolysate, we observed significantly reduced activities of SOD and GPX and a significantly reduced GSH content. Our studies coincide with those reported by Banford et al. [21] who also observed a reduced SOD activity in the erythrocytes of RA patients. An attempt at altering the SOD activity in arthritic patients has been made by use of parenteral injections of bovine dismutase (orgotein), which enzyme appears to have a short-lived antiinflammatory effect [22]. Tarp et al. [23] have reported reduced GPX activity in the erythrocytes and a reduced GSH content in the serum of RA patients. Therefore, the reduced enzymatic antioxidant levels obtained in the study may have been due to abnormal enzyme regulation, as there was a failure of SOD and GPX induction in spite of the increased free radical production. The high lipid peroxide level obtained in the plasma can be attributed to the reduced level of GSH and low activity of the enzymatic antioxidants.

In the present study, we have also observed a good positive correlation between pairs of the parameters assayed in the hemolysate, which reflects the fact that a change in one parameter depends on another parameter. Therefore, we conclude that an altered antioxidant status exists in RA patients of South Indian origin. This altered status may contribute indirectly to the pathogenesis of the disease.

The role of free radicals as a primary or secondary cause in the pathogenesis of the disease is still under question. The continued investigation of the role of free radicals in pathological processes is warranted in the hope of further elucidating the mechanism involved in the free radical injury and sources of generation of these radicals, as well as of defining a treatment that will provide a significant protection against the damage caused to the cells as a result of oxidative insult.

\section{REFERENCES}

1. Southorn, P., and Powis, G. (1988): Free radicals in medicine. I-Chemical nature and biologic reactions. Mayo Clin. Proc., 63, 381-389.

2. Greenwald, R.A., and Moy, W.W. (1980): Effect of oxygen derived free radicals on hyaluronic acid. Arthritis Rheum., 23, 455-463.

3. Hurst, N.P., Bessac, B., and Nuki, G. (1984): Monocyte superoxide anion production in rheumatoid arthritis: Preliminary evidence for enhanced rates of superoxide anion production by monocytes from patients receiving penicillamine, sodium aurothiomalate and corticosteroids. Ann. Rheum. Dis., 43, 28-33.

4. McCord, J.M. (1974): Free radicals and inflammation: Protection of synovial fluid by superoxide dismutase. Science, 185, 529-531.

5. Greenwald, R.A., and Moy, W.W. (1979): Inhibition of collagen gelation by action of superoxide radical. Arthritis Rheum., 22, 251-259. 
6. Mapp, P.I., Grootveld, M.C., and Blake, D.R. (1995): Hypoxia, oxidative stress and rheumatoid arthritis. Br. Med. Bull., 51, 419-436.

7. Hamilton, J.A. (1993): Rheumatoid arthritis: Opposing actions of haemopoietic growth factors and slow acting anti-rheumatic drugs. Lancet, 342, 536-539.

8. Nalini, G., Hariprasad, C., Chandrasekaran, A.N., and Poonguzhali, K. (1993): A comparative study of serum deaminases in systemic rheumatic diseases. Br. J. Rheumatol., 32, 11181119.

9. Nalini, G., Hariprasad, C., Chandrasekaran, A.N., Gowri, C., and Poonguzhali, K. (1994): Urinary glycosaminoglycans excretion in rheumatoid arthritis. JIRA, 2, 124-126.

10. Chiu, D., Lubin, B., and Shohet, S.B. (1982): Peroxidative reactions in red cell biology, in Free Radicals in Biology, ed. by Pryor, W.A., Academic Press, New York, Vol. 5, pp. 115153.

11. Winrow, V.R., Winyard, P.G., Morris, C.J., and Blake, D.R. (1993): Free radicals in inflammation: Second messengers and mediators of tissue destruction. Br. Med. Bull., 49, 506-522.

12. Arnett, F.C., Edworthy, S.M., Bloch, D.A., McShane, D.J., Fries, J.F., Cooper, N.S., Healey, L.A., Kaplan, S.R., Liang, M.H., Luthra, H.S., Medsger, T.A., Jr., Mitchell, D.M., Neustadt, D.H., Pinals, R.S., Schaller, J.G., Sharp, J.T., Wilder, R.L., and Hunder, G.G. (1988): The American Rheumatoid Association 1987 Revised Criteria for the Classification of Rheumatoid Arthritis. Arthritis Rheum., 31, 315-324.

13. Omaye, S.T., Turnbull, J.D., and Sauberlich, H.E. (1979): Selected methods for the determination of ascorbic acid in animal cells, tissues and fluids, in Methods in Enzymology, ed. by Mc Cormick, D.B., and Wright, L.D., Academic Press, Inc., New York, Vol. 62, pp. 111.

14. Yagi, K., Nishigaki, I., and Ohama, H. (1968): Measurement of serum TBA-value. Vitamins, 37, 105-112.

15. Moron, M.S., Despierre, J.W., and Mannervik, B. (1979): Levels of glutathione, glutathione reductase and glutathione-S-transferase activities in rat lung and liver. Biochim. Biophys. Acta, 582, 67-78.

16. Rotruck, J.T., Pope, A.L., Ganther, H.E., Swason, A.B., Hafeman, D.G., and Hoekstra, W.G. (1973): Selenium: Biochemical role as a component of glutathione peroxidasepurification and assay. Science, 179, 588-590.

17. Marklund, S., and Marklund, G. (1974): Involvement of the superoxide anion radical in the autooxidation of pyrogallol and a convenient assay for superoxide dismutase. Eur. J. Biochem., 47, 469-474.

18. Drabkin, D.L., and Austin, J.M. (1932): Spectrophotometric studies, spectrophotometric constants for common hemoglobin derivatives in human, dog and rabbit blood. J. Biol. Chem., 98, 719-733.

19. Lunec, J., Halloran, S.P., White, A.G., and Dormandy, T.L. (1981): Free radical oxidation (peroxidation) products in serum and synovial fluid in rheumatoid arthritis. J. Rheumatol., 8, 233-245.

20. Niwa, Y., Sakane, T., Shingu, M., and Yokoyama, M.M. (1983): Effect of stimulated neutrophils from the synovial fluid of patients with rheumatoid arthritis on lymphocytes-a possible role of increased oxygen radicals generated by the neutrophils. J. Clin. Immunol, 3, 228-240.

21. Banford, J.C., Brown, D.H., Hazelton, R.A., Mc Neil, C.J., Sturrock, R.D., and Smith, W. E. (1982): Serum copper and erythrocyte superoxide dismutase in rheumatoid arthritis. Ann. Rheum. Dis., 41, 458-462.

22. Martelli, E.A. (1980): Orgotein-A review. Med. Actual., 16, 97-101.

23. Tarp, U., Stengaard-Pedersen, K., Hansen, J.C., and Thorling, E.B. (1992): Glutathione redox cycle enzymes and selenium in severe rheumatoid arthritis: Lack of antioxidative response to selenium supplementation in polymorphonuclear leucocytes. Ann. Rheum. Dis., 51, 1044-1049. 